\title{
La creación del mundo supralunar según Abraham Ibn Ezra: un estudio comparativo de sus dos comentarios a Génesis 1,14
}

\begin{abstract}
Shlomo SELA *
Bar-Ilan University

Un estudio de las principales obras de los más destacados intelectuales hispanojudíos del siglo XII permite observar que, en algunos lugares, se abstuvieron de apoyar terminantemente la idea de la creación del mundo ex-nihilo, y que tampoco vieron en semejante posición una seria amenaza a la ortodoxia religiosa. Así, por ejemplo, Yehudá ha-Leví (m. 1141), en su Cuzarí, ponía las siguientes palabras en boca del «amigo»: «el problema de la eternidad del mundo y de su creación es sumamente difícil de resolver, y ambas posiciones pueden ser defendidas con admirables argumentos ... y con todo eso, si el creyente en la Torá ve una necesidad lógica en la opinión que apoya la eternidad del mundo o en la idea de que el mundo presente fue precedido por innumerables mundos anteriores, todo esto no supondrá ninguna falta en su creencia de que nuestro mundo actual fue creado hace algún tiempo y que sus primeros

*shlomo@mail.biu.ac.il.

Deseo agradecer a Mariano Gómez Aranda sus sugerencias y su ayuda en la traducción del hebreo al español de las citas de los comentarios de Abraham Ibn Ezra que aparecen en este artículo.

Sefarad 63 (2003) págs. 147-181

(c) CSIC

ISSN 037-0894
\end{abstract}


habitantes fueron Adán y Noé» ${ }^{1}$. Por su parte, Abraham Bar Hiyya (ca. 1065 - ca. 1040), exponiendo y discutiendo en su obra escatológica Megilat ha-Megalle (Libro del revelador) varias teorías indias sobre la creación cíclica del mundo, aportaba también sus propias ideas y afirmaba que «si (los sabios indios) no hubiesen hecho depender el acto de la creación del gobierno de los astros, se habrían acercado a la opinión de nuestros maestros, bendita sea su memoria, que afirmaron que 'en seis mil años se gestó el mundo y en mil fue destruido’ (Sanhedrín 97a)» ${ }^{2}$. Tampoco Maimónides (1135-1204) veía en las teorías contrarias a la creación ex-nihilo una seria amenaza a la creencia religiosa, tal como expone en la segunda parte de la Guía de perplejos: «si se admite la eternidad según la segunda opinión que hemos expuesto, la de Platón, y según la cual también el cielo es perecedero, esta opinión no destruye las bases de la religión y no se sigue de ella la negación del milagro, sino, al contrario, su admisibilidad» ${ }^{3}$. Sin ser una excepción a la indicada regla, Abraham Ibn Ezra (ca. 1089 - ca. 1167), comentador bíblico, astrólogo, astrónomo, matemático, poeta, gramático, filósofo, teólogo, autor de monografías de variadísimos temas y principal protagonista de este artículo, se diferenció y distinguió de sus colegas al menos en dos puntos principales.

En primer lugar, mientras que sus compañeros rechazaban en algunos lugares la posibilidad de una creación ex-nihilo y en otros la apoyaban totalmente ${ }^{4}$, Ibn Ezra, a pesar de ser amante de expresio-

1 Cuzarí I:67. La traducción es mía. Para una versión inglesa véase Book of Kuzari by Judah Hallevi, translated from the Arabic by H. HIRSCHFELD (New York 1946) págs. 47-48.

2 Abraham Bar Hiyya, Sefer Megillat ha-Megalle von Abraham bar Chija, published by A. POZNANSKI, with Introduction and Notes by J. GuTTMAN (Berlin 1924) pág. 11 (la traducción es mía).

${ }^{3}$ Maimónides, Guía de los descarriados, versión castellana y prólogo de L. Dujovne (Buenos Aires 1955) II:25, págs. 135-136.

4 Así, por ejemplo, Maimónides escribía las siguientes palabras en su famosa Epístola sobre la astrología, que envió a un grupo de rabinos provenzales: «la raíz de la Torá es que sólo Dios es la Causa Primera y Él ha creado todo ex-nihilo; quien no acepte esto rechaza lo fundamental y niega su fe» (A. MARX, «The Correspondence between the Rabbis of Southern France and Maimonides about 
nes enigmáticas, lacónicas y ambiguas, nos dejó varias declaraciones en las que se pronunciaba rotundamente en contra de la creación ex-nihilo. Veamos, por ejemplo, su primer comentario a Gen 1,1 , donde interpretaba la etimología del verbo hebreo bara', empleado en el primer capítulo de Génesis para indicar el acto de la creación:

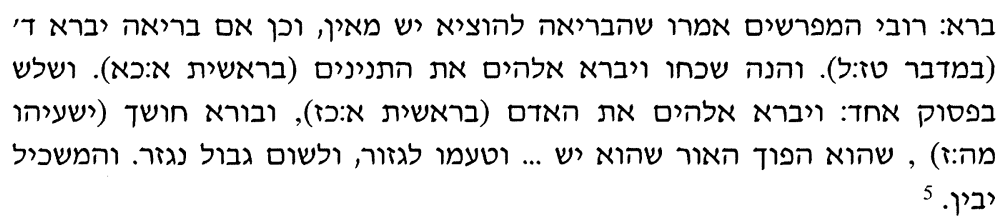

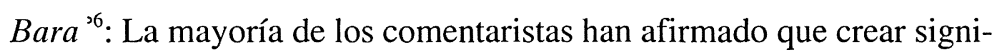
fica extraer algo de la nada, y así [por ejemplo] si Yahveh crea algo nuevo (Num 16,30), pero ellos se han olvidado de creó Elohim los grandes cetáceos (Gen 1,21) y las tres [veces que aparece el verbo bara'] en un sólo versículo: creó Elohim al hombre (Gen 1,27). [También se olvidaron de] creó las tinieblas (Is 45,7) que son lo contrario de la luz que tiene sustancia. El significado de bara' es cortar y poner límite a lo que está cortado. Y el entendido entenderá.

No es difícil averiguar la intención de Ibn Ezra. Los cetáceos fueron creados de las aguas, el hombre tampoco fue creado ex-nihilo, sino «del polvo del suelo» (Gen 2,7). El ejemplo de la creación de las tinieblas, que no son más que ausencia de luz, es claramente explicado por el mismo Ibn Ezra en su comentario. Basándose en estos tres ejemplos extraídos del texto bíblico, Ibn Ezra concluye que crear no significa 'extraer algo de la nada', sino 'cortar y poner límite'. Digamos ya que tanto los supercomentaristas medievales de Ibn Ezra como los investigadores modernos han hecho hincapié en

Astrology», HUCA 3 [1926] pág. 353 [la traducción es mía]). No es casual que Maimónides incluyera este ferviente manifiesto en favor de la creación ex-nihilo precisamente en esta fogosa epístola destinada a demoler las doctrinas de los astrólogos, pues el principal blanco contra el que se arrojan sus afiladas flechas era probablemente el astrólogo Abraham Ibn Ezra.

5 Primer comentario a Gen 1,1 en A. WEIZER (ed.), Perušé ha-Torá le-Rabbenu Abraham ibn Ezra (Jerusalem 1976) (de aquí en adelante Comentario a la Torá) vol. I, págs. 11-12.

' Es decir, 'crear'. 
que este autor rechazaba una creación del mundo ex-nihilo. Sería vano insistir en este punto ${ }^{7}$.

En segundo lugar, Ibn Ezra se diferenció de los demás comentaristas en haber propuesto una visión dicotómica de la creación, según podremos comprobar en su segundo comentario al primer versículo de Génesis:

ועוד, כי אין מלת ברא כאשר חשבו רבים לעשות את שאינו ישנו. והמוכיח

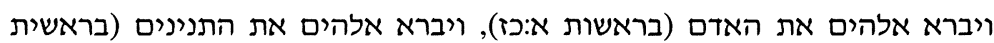

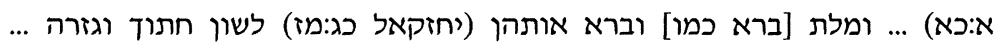

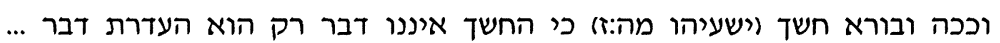

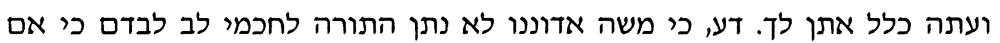

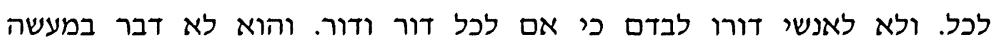
בראשית כי אם בעולם השפל שנברא בעבור האדם, על כן לא הזיר הזכיר המלאכים לאים

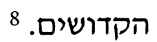

Además, en contraste con lo que muchos han opinado, la palabra bara' no significa crear algo ex-nihilo. Esto queda comprobado por creó Elohim al hombre (Gen 1,27), creó Elohim los grandes cetáceos (Gen 1,21), la palabra [bara'empleada en] y las hagan trozos [con sus espadas] $($ Ez 23,47) donde significa corte e incisión ... y también creó las tinieblas (Is 45,7), ya que las tinieblas no son sustancia sino simplemente la ausencia de sustancia ... Y ahora te presentaré una regla fundamental: sabrás que Moisés, nuestro señor, no dio la Torá sólo a los cultos sino a todos en general, ni la dio solamente a su propia

7 Así escribía el español José Bonfils (segunda mitad del siglo XIV), uno de los mejores alumnos de Ibn Ezra y un gran conocedor de su obra exegética y científica, en su Safnat Pa'aneach, un supercomentario al primer comentario de Ibn Ezra al Pentateuco: «Dijo José: sabrás que la opinión de Rabí Abraham es idéntica a la opinión de los filósofos, es decir, que ... los cuatro elementos (sublunares) ya existían antes del Génesis». Véase J. BonfiLs, Sophnat Pane'ach, Ein Beitrag zur Pentateuchexegeses des Mittelalters von D. Herzog (Heidelberg 1911-1930) págs. 28-29. Sobre la opinión de los supercomentaristas de Ibn Ezra del siglo XIV, en su gran mayoría españoles, véase D. SCHWARTZ, The Philosophy of a Fourteenth Century Jewish Neoplatonic Circle (Jerusalem 1996) [en hebreo] págs. 30 y 63116. Para una opinión moderna, véase I. LANCASTER, «Abraham Ibn Ezra's Definition of Creation», en Abraham Ibn Ezra y su tiempo, ed. F. DíAz EsTEBAN (Madrid 1990) págs. 175-180.

${ }^{8}$ Segundo comentario a Gen 1,1 en Comentario a la Torá, vol. I, págs. 155-156. 
generación sino a todas las generaciones. Y cuando hizo mención del génesis del mundo se refirió sólo al mundo inferior que fue creado para el hombre, y por lo tanto no aludió a los ángeles santos.

Advertimos entonces, en la primera parte de esta cita, la misma línea de pensamiento ya expresada en el primer comentario a Génesis, o sea, que el concepto bíblico de creación no implica una creación ex-nihilo. Sin embargo, observamos luego una significativa novedad. Con respecto a la visión bíblica de la creación del mundo, se hace aquí una clara distinción entre el «mundo inferior» y el mundo de los «ángeles santos». Recordemos que en la visión aristotélica prevaleciente en la Edad Media, y compartida por Ibn Ezra, el mundo era rigurosamente dividido en dos dominios. Por un lado, el mundo sublunar, sujeto a la generación y a la corrupción, constituido materialmente por la mezcla de los cuatro elementos fundamentales (fuego, aire, agua y tierra), cuyo movimiento natural es rectilíneo (hacia o desde el centro de la tierra); por el otro, el mundo supralunar, eterno e inmutable, constituido materialmente por el llamado «quinto elemento», que se mueve solamente en círculos perfectos. Resulta entonces que el «mundo inferior» es el mundo sublunar, mientras que el mundo de los «ángeles santos» no es sino el mundo supralunar ${ }^{9}$. Más aún, según Ibn Ezra la narración bíblica de la creación del mundo, tal y como fue hecha por Moisés (considerado tradicionalmente como el autor del Pentateuco), no hace referencia directa al mundo supralunar, sino solamente al mundo sublunar. Ibn Ezra explica que el motivo de tal discriminación fue el deseo de Moisés de que la Torá fuera transmitida a todas las generaciones y a todo el mundo en general, y que no se convirtiera en un mensaje elitista destinado exclusivamente a los cultos.

\footnotetext{
9 Ver en este sentido la declaración paralela y similar, aunque más concisa, que

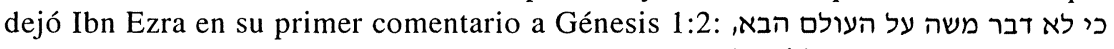
שהוא עולם המלאכים, כי אם על עולם ההויה והשחתה. Traducción: «Ya que Moisés no se refirió [en su relato de la creación del mundo] al mundo futuro, que es el mundo de los ángeles, sino al mundo de la generación y de la corrupción» (Comentario a la Torá, vol. I, pág. 14).
} 
Esta declaración despierta una larga serie de interrogantes acerca del genuino pensamiento de Ibn Ezra: ¿cuál es el significado de esta diferencia entre los mundos sublunar y supralunar? ¿Quiere decir que las dos partes del Universo fueron creadas en tiempos diferentes y que cada una de ellas sufrió un tipo de creación diferente? ¿O quizás ambos fueron creados simultáneamente y, puesto que el relato bíblico de la creación del mundo se desentendió completamente de la creación del mundo supralunar, debemos encontrar fuera del texto bíblico las pistas necesarias para describir su creación? ¿Es cierto que, según Ibn Ezra, el relato del Génesis se desentendió completamente de la creación del mundo supralunar? ¿O quizá, por el contrario, el mismo texto bíblico insinúa algunas pistas para entender la relación entre la génesis de ambos mundos? Además, ¿cuál es el significado de la afirmación de Ibn Ezra de que «Moisés, nuestro señor, no dio la Torá sólo a los cultos sino a todos en general»? ¿Deberíamos entenderla, según conjeturó el ya fallecido Prof. A. Funkenstein, como una afirmación por parte de Ibn Ezra para indicar que «los cuerpos celestes aparecen en el relato bíblico de la creación desde la perspectiva especial del hombre común, sin ninguna referencia a su esencia o a su verdadera naturaleza»? Finalmente, ¿deberíamos entender que la intención genuina de Ibn Ezra era exhortar a sus lectores y alumnos a estudiar los libros de la ciencia griega, ya que sólo de ellos se pueden extraer los secretos de la creación del mundo supralunar, y no de las Escrituras, que «hablan en lenguaje humano» y reflejan sólo el punto de vista de las multitudes? ${ }^{10}$

\footnotetext{
${ }^{10}$ A. Funkenstein, Theology and the Scientific Imagination (Princeton, New Jersey 1986) pág. 216: “'The Scriptures speak a human language', means simply that Scripture adapts themselves to the point of view of the multitude. They do not contradict science, but neither do they conflict all of it ... Time and again, Ibn Ezra emphasizes that Genesis is not a scientific, comprehensive account of the creation of the world ex-nihilo, but rather the account of the formation of the sublunar realm through natural processes, that is, laws. Genesis only tells the facts immediately pertinent to the formation and status of man. Even the celestial bodies appear in the narrative of creation only from the vantage point of the average man, not with any reference to their essence or true nature».
} 
Este artículo estará destinado a dar respuesta a estos interrogantes, especialmente en todo lo relacionado con la creación del mundo supralunar. A pesar de haberse dedicado de lleno al estudio de las ciencias griegas y árabes, de haber compuesto un admirable corpus de obras científicas, y de haber otorgado allí una importancia primordial al estudio de los cuerpos celestes y su influencia sobre la tierra ${ }^{11}$, muy pocas son las pistas que dejó Ibn Ezra en sus tratados científicos astronómicos o astrológicos sobre su opinión acerca de la génesis de los cuerpos celestes. Por el contrario, si buscamos amplia información acerca de su opinión sobre la creación del mundo, tanto sublunar como supralunar, la hallaremos justamente en sus comentarios bíblicos. Esta característica fundamental del modus operandi de Ibn Ezra nos sugiere, o más bien nos impone, nuestra metodología: hacer uso principalmente de sus comentarios bíblicos. Sin embargo, debido a que Ibn Ezra normalmente no acostumbraba a expresar con excesiva libertad sus opiniones sobre temas filosóficos centrales, nos va a ser necesario prepararle una trampa metodológica. Pensamos que el ardid más adecuado para atrapar al escurridizo Ibn Ezra será concentrar nuestros esfuerzos en el estudio meticuloso de sus dos comentarios a Gen 1,14 . Teniendo como objetivo principal este versículo bíblico en el que se describe la creación de las luminarias, pensamos que en sus dos comentarios Ibn Ezra no pudo eludir el dar su opinión genuina, o, por lo menos, creemos que tuvo que haber dejado alguna pista significativa para que podamos descubrir su concepción sobre la creación del mundo supralunar.

\section{EL PRIMER COMENTARIO DE IBN EZRA A GEN 1,14}

En Luca, entre 1143 y 1145, Ibn Ezra compuso su primer comentario al Pentateuco ${ }^{12}$, y es en esta obra, conservada en forma fragmentaria, donde leemos su explicación a Gen 1,14:

\footnotetext{
"Sobre la obra científica de Abraham Ibn Ezra, véase S. SELA, «Abraham Ibn Ezra's Scientific Corpus - Basic Constituents and General Characterization», Arabic Sciences and Philosophy 10 (2001) págs. 91-149.

${ }^{12}$ Acerca de la producción literaria de Ibn Ezra en Italia, véase: D. Rosin, «Die Religionsphilosophie Abraham Ibn Esra's», Monatsschrift für Geschichte und
} 


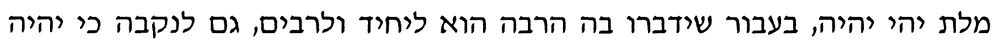

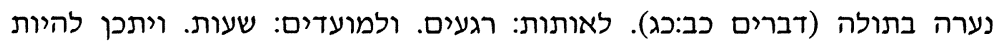

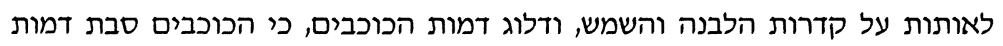

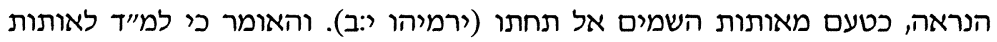
נוסף, לא אמר כלום. 13

La palabra yehi es yihyeh (será), por su gran frecuencia se usa tanto para el singular, el plural y en femenino, como en si una muchacha virgen está [prometida] (Deut 22,23); le- otot [significa] minutos, y lemóadim [significa] horas, aunque es posible que le-otot aluda a los eclipses de luna y de sol, y a la permutación de las formas de las estrellas, ya que las estrellas son la causa de la imagen visual, según el significado de ni os aterréis por los signos celestes (Jer 10,2). Y quien diga que la lamed en le-'otot es redundante, no ha dicho nada.

Después de leer las extremadamente concisas expresiones de Ibn Ezra en este pasaje, el lector comprenderá perfectamente por qué su primer comentario al Pentateuco fue titulado «el corto», pues más que un comentario da la impresión de ser el resumen de un comentario. Sin embargo, este pasaje es muy útil para observar algunas características de la exégesis de Ibn Ezra. Se nota su preocupación por los aspectos lingüísticos y gramáticales del texto bíblico, su propensión a utilizar el corpus bíblico para corroborar y demostrar sus hipótesis y opiniones, y su inclinación a presentar, sin ningún temor de caer en el anacronismo, las opiniones de sus antecesores para estudiar y ampliar la perspectiva del tema que discute. A pesar de la extrema concisión, algunos puntos merecen ser comentados. El lector no entiende por qué le-'otot debe significar necesariamente 'minutos', ni tampoco por qué mo ádim son 'horas', pero sí queda claro que según Ibn Ezra estos términos problemáticos son una alusión a

Wissenschaft des Judentums 42 (1898) pág. 25; L. FLEISCHER, «La obra literaria de Abraham Ibn Ezra en Roma» [en hebreo], 'Otzar ha-Hayim 8 (1932) págs. 97-100, 129-31, 148-150, 169-71; L. FLEISCHER, «La obra literaria de Abraham Ibn Ezra en Luca» [en hebreo], en Abraham Ibn Ezra. A Collection of Articles on his Life and Work (Tel Aviv 1970) págs. 107-124. En Roma, Ibn Ezra compuso Sefer Moznayim, y en Luca Sefer ha-Yesod y Sephat Yeter, todas ellas obras para el estudio de la gramática hebrea.

${ }^{13}$ Comentario a la Torá, pág. 16. 
ciertos períodos del tiempo cíclico. El lector tampoco sabe cuál es el origen de las opiniones anónimas que Ibn Ezra expone apresuradamente en la parte final del pasaje. Sólo después de leer la parte final de su segundo comentario comprenderá el lector la importancia que uno de los geonim fue quien se refirió a le- otot como una alusión a los eclipses de luna y de sol, que Yehudá ibn Balaam fue quien se basó en Jer 10,2 para otorgar una explicación astrológica a este término, y que el caraíta Rabi Yešua fue quien propuso como redundante la lamed de le-'otot, al interpretar esta parte del versículo como una alusión al tiempo ritual ${ }^{14}$. Inmediatamente después, en su primer comentario Ibn Ezra pasa abruptamente al tema central:

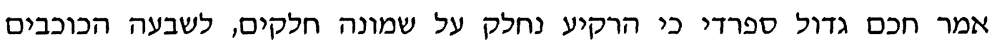

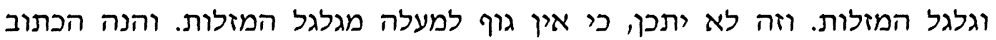

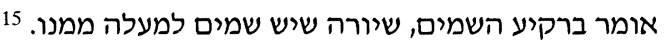

Ha dicho un gran sabio sefardí que el firmamento se divide en ocho partes, correspondientes a los siete astros y a la esfera de las constelaciones del zodíaco. Pero esto es imposible, ya que no hay ningún cuerpo [físico] sobre la esfera de las constelaciones del zodíaco, por eso las Escrituras dicen en el firmamento de los cielos, para indicar que hay cielos que están sobre él [es decir, sobre el firmamento].

Quien lea este fragmento por primera vez se quedará sin duda sorprendido: ¿qué tiene que ver esta alusión a la constitución del cosmos con la explicación del texto de Gen 1,14? ¿En qué consiste la diferencia de opinión entre este «gran sabio sefardí» y Abraham Ibn Ezra? ¿Qué objetivo persigue nuestro autor al presentar en la parte más central de su comentario una polémica con este sabio mencionado? Y finalmente, ¿quién es este «gran sabio sefardí»? Esta última pregunta nos parece un buen punto de arranque. Afortunadamente, la identidad del «gran sabio sefardí» queda revelada en el segundo comentario a Gen 1,6, cuyo estudio será sumamente útil para comprender las intenciones de Ibn Ezra al explicar Gen 1,14:

${ }^{14}$ Comentario a la Torá, págs. 161-162.
${ }^{15}$ Comentario a la Torá, pág. 16. 


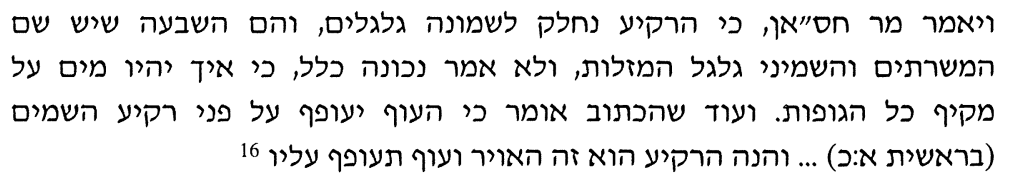

Dijo Mar Hasán que el firmamento está dividido en ocho esferas, que son las siete en las cuales están los planetas (mešaretim) ${ }^{17}$, y la octava, que es la esfera de las constelaciones del zodíaco. Pero él está totalmente equivocado, ya que no hay agua sobre lo que rodea a todos los cuerpos. Además las Escrituras hablan sobre aves que vuelan por la superficie del firmamento de los cielos (Gen 1,20)... [llegamos] entonces [a la conclusión de que] el firmamento es el aire y las aves vuelan sobre él.

Advertimos que la identificación del firmamento (raqi $\left.{ }^{i} a\right)$ con el cosmos de ocho esferas, siete para los planetas y la octava para la esfera de las constelaciones del zodíaco, aparece en el primer comentario a Gen 1,14 casi con las mismas palabras que en el segundo comentario a Gen 1,6. Además, «lo que rodea a todos los cuerpos» en este último comentario no es sino «la octava esfera de las constelaciones del zodíaco» del primero. Por estas semejanzas concluimos que el «gran sabio sefardí» del primer comentario a Gen 1,14 y Mar Hasán del segundo comentario a Gen 1,6 son la misma persona. Una lectura comparada de ambos textos nos deja también entender que, al apodar a Mar Hasán «gran sabio sefardí», la intención del

\footnotetext{
${ }^{16}$ Comentario a la Torá, pág. 160.

${ }^{17}$ La palabra mešaretim significa literalmente en hebreo 'sirvientes', pero Ibn Ezra la utilizó frecuentemente en toda su obra para expresar el concepto científico de 'planetas'. Este vocablo es un excelente ejemplo de su estrategia original para crear un nuevo vocabulario científico hebreo. En su opinión, no siempre es necesario traducir del árabe al hebreo, ya que en el texto bíblico se esconden algunos términos cuyo significado científico original se ha olvidado, pero puede, o debe, ser restaurado. Fiel a este enfoque de la lengua hebrea, Ibn Ezra extrajo la palabra mešaretim de Sal 103,21 y explicó su nuevo significado en el comentario que escribió a este mismo versículo. Sobre la estrategia lingüística de Ibn Ezra y el uso de este término, véase S. SELA, Abraham Ibn Ezra and the Rise of Medieval Hebrew Science (Leiden 2003) págs. 129-130.
} 
descarado Ibn Ezra no era tanto elogiarlo como denigrarlo ${ }^{18}$. Sin embargo, la configuración cósmica que según Ibn Ezra sustentaba Mar Hasán no es sino la imagen científica resumida del mundo vigente en la Edad Media, la misma con la cual Ibn Ezra se identificaba plenamente, según puede comprobarse leyendo su obra literaria ${ }^{19}$. Entonces, si ambos compartían la misma concepción cosmológica, ¿qué es lo que despertaba la objeción de Ibn Ezra?

La verdadera diferencia de opinión entre los dos no residía en su concepción científica del mundo, que fundamentalmente era idéntica, sino en una explicación radicalmente diferente del significado de la palabra hebrea raqi $a$. Mientras que para Mar Hasán este término denominaba a todo el cosmos, Ibn Ezra rechazaba rotundamente esta explicación extrayendo de su arsenal exegético dos armas poderosas. En primer lugar, utiliza el texto de Gen 1,6, donde se afirma que «haya firmamento (raqi ${ }^{\prime} a$ ) en medio de las aguas y separe unas aguas de otras», para llegar a la conclusión de que Mar Hasán «está totalmente equivocado», porque aceptar su opinión es equivalente a afirmar que «hay agua sobre lo que rodea a todos los cuerpos», o sea, que hay agua sobre la esfera de las constelaciones del zodíaco. En segundo lugar, Ibn Ezra se refiere a Gen 1,20 porque aquí las aves aparecen volando «por la superficie del firma-

\footnotetext{
${ }^{18}$ Esta impresión queda confirmada al leer el Sefer ha- Ibbur (Libro de la intercalación), una obra destinada a analizar científicamente el calendario hebreo, escrita por Ibn Ezra en Verona, 1146, poco tiempo después de haber escrito el primer comentario al Pentateuco. En esta obra, Ibn Ezra se mofa del «gran sabio sefardí», y escribe a sus lectores: «Cuídate bien de no poner atención en lo que dijo Ben Hasán el sefardí, que escribió tres libros sobre el secreto del calendario pero nada de lo que dijo tiene sentido»: Abraham Ibn Ezra, Sefer halbbur, ed. S. Z. H. HALBERSTAM (Lyck 1874) pág. 10b. La obra relativa al calendario de Mar Hasán fue también criticada por el barcelonés Abraham Bar Hiyya en su propio Sefer haIbbur: véase Abraham Bar Hiyya, Sefer ha Ibbur, ed. T. PHILIPOVSKY (London 1851) págs. 54, 94.

${ }^{19}$ Ibn Ezra defiende de forma admirable el modelo de las ocho esferas (siete para siete planetas y la octava para las estrellas fijas) en la introducción a la segunda versión del Sefer ha-Téamim: véase Abraham Ibn Ezra, Sefer ha-Téamim (segunda versión), ed. N. BEN MENACHEM (Jerusalem 1941) pág. 2. Comentaremos más adelante este pasaje.
} 
mento de los cielos», y esto equivale a decir «que el firmamento (raqi ${ }^{\prime} a$ ) es el aire y las aves vuelan sobre él». Pero en opinión de Mar Hasán el firmamento comprende las ocho esferas cósmicas, lo cual, según Ibn Ezra, equivale a decir algo tan absurdo como que las aves, que están compuestas de los cuatro elementos del mundo sublunar, vuelan sobre la octava esfera, que es la esfera de estrellas más externa del cosmos y que está constituida por el quinto elemento, eterno e inmutable. Esta afirmación echaría por tierra el concepto medieval del cosmos. La conclusión de Ibn Ezra es simple y tajante: el firmamento (raqi ía) del texto bíblico, creado en el tercer día y por cuya superficie vuelan las aves, no es sino la atmósfera, parte integral del mundo sublunar.

También en su primer comentario a Gen 1,14 Ibn Ezra arremete contra la misma interpretación del firmamento del «gran sabio sefardí», pero en este caso Ibn Ezra afirma que «no hay ningún cuerpo físico sobre la esfera de las constelaciones del zodíaco», queriendo dar a entender que los cuerpos celestes, es decir, las estrellas, están distribuidos en las primeras ocho esferas, y que sobre la octava gira la muy problemática novena esfera en la que no hay astros ${ }^{20}$. La intención de Ibn Ezra es manifestar a sus lectores que la tesis del «gran sabio sefardí» es disparatada porque está en contradicción con el texto de Gen 1,14 , y por esta razón se vale del texto del mismo versículo que está comentando, y escribe: «por eso las Escrituras

\footnotetext{
${ }^{20}$ De acuerdo con la visión cosmológica vigente en la Edad Media, la novena esfera estaba provista de las siguientes características: (a) representa la capa superior y exterior del cosmos; (b) transmite a las restantes ocho esferas el movimiento diurno, que se efectúa de este a oeste sobre el plano del ecuador celeste; (c) a diferencia de las demás, la novena es una esfera «vacua» que no transporta ninguna estrella. Ibn Ezra acostumbraba a llamar a esta esfera ha-galgal ha- élion ('esfera superior') o circulus altissimus, y la solía mencionar, con serios propósitos exegéticos, en sus comentarios bíblicos, especialmente para defender importantes argumentos exegéticos y teológicos. Su primer comentario a Gen 1,14 es un ejemplo. Para un estudio de la novena esfera y de la manera en que fue considerada por Abraham Ibn Ezra, véase S. SELA, Abraham Ibn Ezra and the Rise, págs. 224-233.
} 
dicen 'en el firmamento de los cielos' para indicar que hay cielos que están sobre él [es decir, sobre el firmamento]».

No en vano Ibn Ezra hizo hincapié en la expresión problemática y enigmática «en el firmamento de los cielos» (bi-reqi'a hasamayim). A pesar de que «los cielos» aparecen ligados de alguna manera al «firmamento», en última instancia el acto creador se produce en 'el firmamento' (bi-reqi á) y no en 'los cielos' (ha-šamayim). Por lo tanto, establecer el significado de la palabra raqi $a$ significa averiguar dónde fueron creados los cuerpos celestes, $\mathrm{y}$, a fin de cuentas, permite también determinar qué es lo que fue creado en el cuarto día. Este planteamiento estaba bien claro tanto para el «gran sabio sefardí» como para Abraham Ibn Ezra, y esa es la razón por la cual los dos ponían tanto énfasis en averiguar el significado de la palabra raqi á. La opinión del «gran sabio sefardí», tal como fue mencionada por Ibn Ezra, es bien clara: dado que el raqi á bíblico es equivalente al mundo cósmico de las esferas supralunares, lo que fue creado en el cuarto día fueron los cuerpos físicos de la luna, el sol y las estrellas, tal como son estudiados y conocidos por los astrónomos. Pero Ibn Ezra se opone rotundamente a esta interpretación porque contiene dos errores fatales: en primer lugar, la palabra raqi á ('firmamento') no se refiere al mundo supralunar en su totalidad y, en segundo lugar, el «gran sabio sefardí» no ha tenido en cuenta que el texto bíblico dice explícitamente que el acto creador se produjo bi-reqi a ha-samayim ('en el firmamento de los cielos') y, en opinión de Ibn Ezra, esta compleja expresión no se puede ignorar. Por esta razón, en la última parte de su comentario explica el significado de la palabra 'cielos' y expresa su opinión sobre el objetivo de la creación de las luminarias y las estrellas:

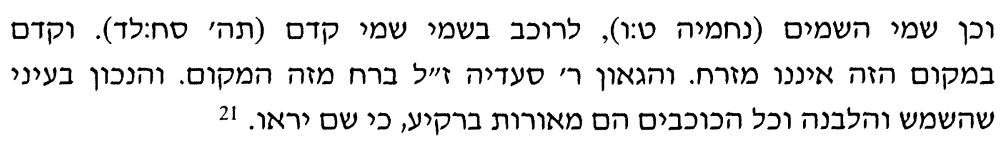

${ }^{21}$ Comentario a la Torá, págs. 16-17. 
También [puedes encontrar] los cielos de los cielos (Neh 9,6), al que cabalga sobre los cielos de los cielos desde antiguo (qedem) ${ }^{22}$ (Sal 68,34). La palabra qedem en este versículo no significa 'oriente'. Y el gaón Rabi Saadia, bendita sea su memoria, eludió [la explicación de] ese asunto. Y en mi opinión lo cierto es que el sol y la luna y todas las estrellas son las luminarias en el firmamento, porque ahí se ven.

No solamente con respecto a Gen 1,14 o a Gen 1,20 se enfrentó Ibn Ezra al problema de la dicotomía de los términos raqi 'a ('firmamento') y samayim ('los cielos'), pues al comentar Sal 19,2, en cuyo texto «cielo» $\mathrm{y}$ «firmamento» aparecen íntimamente relacionados por el paralelismo de expresiones ${ }^{23}$, Ibn Ezra nos informa de que, en su opinión, los cielos son «los movimientos de las esferas», «las mansiones de las estrellas», mientras que el firmamento es «el aire, según expliqué en mi comentario a Génesis» ${ }^{24}$. En otros lugares, haciendo hincapié en que la palabra hebrea samayim tiene forma dual, Ibn Ezra afirma que «los cielos» se refieren a un par de lugares cósmicos estratégicos ${ }^{25}$. En el primer comentario a Gen 1,14, Ibn Ezra no estaba tan interesado en la localización del mundo supralunar como en su edad o antigüedad, y con esta intención remarca la homonimia de la palabra hebrea qedem, que aparece en Sal

\footnotetext{
${ }^{22}$ En Hebreo qedem puede ser entendido como 'antigüedad', pero también como 'oriente'.

${ }_{23}^{23}$ «os cielos (ha-samayim) narran la gloria de Dios y la obra de sus manos pregona el firmamento (ha-raqi 'a)».

${ }^{24}$ Comentario a Sal 19,2 en Miqra 'ot Gedolot (Venice 1525; reimpr. Jerusalem

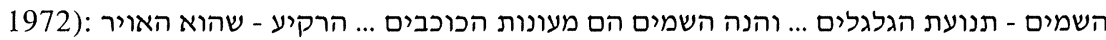
כמו שפירשתי בפרשת בראשית. : כוסית.

${ }^{25}$ Véase segundo comentario a Gen 1,1, comentario largo a Ex 12,6 y Sefer haŠem (I. LEVIN [ed.], Abraham Ibn Ezra: Reader. Annotated texts with Introductions and Commentaries [New York - Tel Aviv 1985] pág. 420), donde Ibn Ezra indica tres pares alternativos y complementarios de lugares cósmicos estratégicos: (1) caput draconis et cauda, o sea, los dos lugares de intersección entre la octava y novena esferas; (2) los dos polos cósmicos; (3) los dos hemisferios celestes. Sobre esta explicación del termino samayim, véase S. SELA, Astrology and Biblical Exegesis in the Thought of Abraham Ibn Ezra (Ramat Gan 1999) [en hebreo] págs. 270-273.
} 
68,34 y que puede ser entendida como 'antigüedad' y como 'oriente'. Al decir que en su opinión qedem no significa 'oriente', Ibn Ezra nos insinúa que «los cielos» de los versículos Sal 68,34, Neh 9,6 y Gen 1,14 señalan al mundo supralunar que precedió a la creación del mundo tal como aparece en el primer capítulo de Génesis. Ibn Ezra también aprovecha esta oportunidad para lanzar sus dardos contra Saadia Gaon, quien, como «el gran sabio sefardí», también expresó una opinión a favor de la creación ex-nihilo de la totali$\mathrm{dad}^{26}$. Para finalizar, siguiendo con las alusiones indirectas, haciendo uso de su mejor estilo lacónico y guardando un total silencio acerca de la formación física de las luminarias, nos revela Ibn Ezra por qué éstas no fueron creadas en los cielos, sino en el firmamento: en su opinión, las luminarias fueron creadas en el firmamento «porque ahí se ven».

Quedan así definidas las dos posiciones antagónicas siguientes:

a) El «gran sabio sefardí» opina que el raqi áa bíblico es equivalente al mundo cósmico de las esferas supralunares y que en el cuarto día fueron creados los cuerpos físicos de la luna, el sol y las estrellas. Todo esto presupone la idea de que la génesis bíblica es equivalente a la creación ex-nihilo y total del mundo, tanto del mundo sublunar como del mundo supralunar.

b) Ibn Ezra opina que la creación de las luminarias, según es relatada en Gen 1,14, no atañe al mundo supralunar, o sea al samayim, sino que es un acto que ocurre en el raqi $a$, o sea en el mundo sublunar, y que tiene como consecuencia que aquellas puedan ser vistas. No se trata de la creación física del mundo supralunar, cuya existencia era anterior a la génesis bíblica, sino de la primera vez en que los cuerpos celestes podían ser vistos desde el mundo sublunar, o sea, desde la tierra.

\footnotetext{
${ }^{26}$ Saadia Gaon, Ha-emunot ve-ha-deot (Las creencias y las opiniones), edición y traducción de Y. KAFAH (Jerusalem 1999) pág. 33-75.
} 


\section{EL SEGUNDO COMENTARIO DE IBN EZRA A GEN 1,14}

En 1148 Ibn Ezra abandonó Italia y se estableció en Provenza ${ }^{27}$. Después se trasladó al norte de Francia, muy posiblemente a Ruán, donde, como es sabido, compuso una segunda versión de los mismos comentarios bíblicos que ya había escrito en Italia ${ }^{28}$. Entre ellos destaca su segundo comentario al Pentateuco, del cual se ha conservado un fragmento del comentario a Génesis y el segundo comentario a Éxodo completo. Veamos el comienzo de su segundo comentario a Gen 1,14:

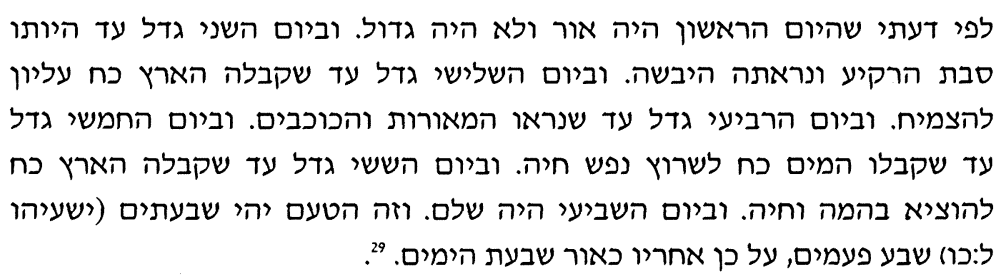

En mi opinión en el primer día hubo luz pero no fue grande. En el segundo día [la luz] se acrecentó hasta ser la causa del firmamento y se vio la tierra firme. En el tercer día [la luz] aumentó hasta que la tierra recibió una fuerza superior para hacer germinar [los vegetales]. En el cuarto día [la luz] se acrecentó hasta que fueron vistas las luminarias y las estrellas. En el quinto día [la luz] creció hasta que las aguas recibieron una fuerza para producir seres vivientes en abundancia. En el sexto día [la luz] aumentó hasta que la tierra recibió una fuerza para generar las bestias y los animales. En el séptimo día [la luz] fue completa. Este es el significado de siete [más

\footnotetext{
${ }^{27}$ Para su obra científica en Provenza, véase S. SELA, «Abraham Ibn Ezra's Scientific Corpus», págs. 106-107, 115-131.

${ }^{28}$ Para una discusión sobre la posible residencia de Ibn Ezra en Ruán y su producción literaria en el norte de Francia, véase D. Rosin, «Die Religionsphilosophie Abraham Ibn Esra's», Monatsschrift für Geschichte und Wissenschaft des Judentums 42 (1898) pág. 25; L. FLEISHER, «Abraham Ibn Ezra en Francia», Mizrah veMáarab 4 (1930) págs. 352-360; 5 (1932) págs. 38-46, 217-224, 289-300; N. GolB, The Jews in Medieval Normandy (Cambridge 1998) págs. 3-5, 264-267.

${ }^{29}$ Comentario a la Torá, pág. 161.
} 
fuerte] (Is 30,26), es decir, siete veces, y por eso [está escrito] después como la luz de los siete días.

Es notable que Ibn Ezra haya elegido precisamente el comienzo de su segundo comentario a Gen 1,14 para comunicar su visión de conjunto de la creación del mundo. Esta es una clara indicación de la importancia que él, como exegeta, le otorgaba a este versículo y al acto creador del cuarto día en el marco de los siete días de la creación. En su opinión, claramente influida por ideas neo-platónicas, estos siete días pueden ser caracterizados como un proceso gradual de emanación y aumento de la luz ${ }^{30}$. A medida que la luz se difunde y se expande, los diferentes seres son creados o vistos. Ciertos elementos de esta idea podían ser ya percibidos en forma embrionaria en el primer comentario a Gen 1,14, ya estudiado en la sección anterior ${ }^{31}$. Es conveniente también prestar atención a la nomenclatura especial empleada por Ibn Ezra en esta sucinta descripción de la creación. Refiriéndose a la germinación de los vegetales, él afirma que «la tierra recibió una fuerza superior», y con respecto a la creación de la flora y fauna dice que «la tierra recibió una fuerza para generar». Estas expresiones son utilizadas con frecuencia por Ibn Ezra para indicar la idea, fuertemente imbuida de carácter teológico, de que algún cuerpo sublunar recibe una emanación o influencia astrológica de algún cuerpo supralunar por orden divina ${ }^{32}$. Cabe entonces preguntarse: ¿de qué cuerpos celestes pudo

\footnotetext{
${ }^{30}$ No es descartable que esta idea haya sido también inspirada por el comentario a este mismo versículo de Saadia Gaon, muy admirado pero también criticado por Ibn Ezra. Según aquel, las luminarias fueron creadas a partir de la gran luz, la luz primigenia; Saadya's Commentary on Genesis, edited with Introduction, Translation and notes by M. ZUCKER (New York 1984) pág. 229.

${ }^{31} \mathrm{Si}$ en la introducción al segundo comentario a Gen 1,14 Ibn Ezra nos comunica que «en el cuarto día [la luz] se acrecentó hasta que fueron vistas las luminarias y las estrellas», en la frase final de su primer comentario a este mismo versículo Ibn Ezra llega a la conclusión de que «en mi opinión lo cierto es que el sol y la luna y todas las estrellas son las luminarias en el firmamento, porque ahí se ven».

${ }^{32}$ Véanse, inter alia, los siguientes lugares en su obra científica y exegética: $S e$ fer Mišpetei ha-Mazalot, Vatican MS Ebr. 477, fols. 72a; 73b, 81a, 81b; Sefer haTe 'amim (primera versión), Paris, Bibliothèque Nationale de France, MS Héb. 1056, fol. 42b; Sefer ha-Téamim (segunda versión), ed. N. BEN MENACHEM
} 
ser recibida esa fuerza superior para que germinaran los vegetales en el tercer día, o sea, un día antes de la creación de las luminarias y las estrellas? Inmediatamente después de esta visión global de la creación, pasa Ibn Ezra a la parte central de su comentario:

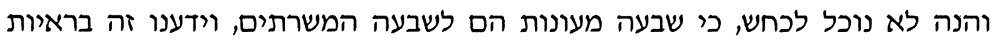

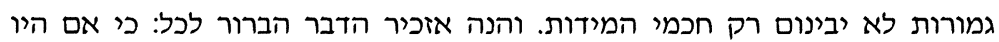

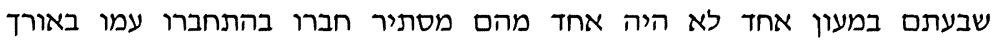

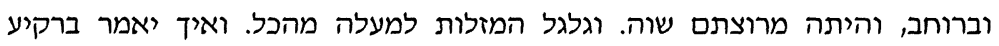

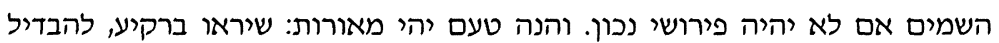

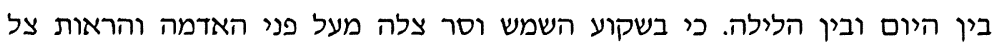

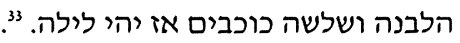

No podemos negar que existen siete esferas (me onot) ${ }^{34}$ para los siete planetas (mešaretim) ${ }^{35}$, y esto lo sabemos con la ayuda de pruebas indiscutibles que sólo los geómetras podrán entender. Mencionaré sólo aquello que es evidente para todos: Si los siete [planetas] estuviesen todos ellos en una sola esfera, entonces sería imposible que alguno de ellos ocultase a su compañero cuando entrara en conjunción con él, tanto en longitud como en latitud, y además todos correrían a la misma velocidad. La esfera de las constelaciones del zodíaco está sobre todos ellos, entonces,

(Jerusalem 1941) págs. 11, 17, 19; 22; Sefer ha-Me'orot, en J. L. FleISCHER (ed.), Sefer ha-Me orot, Sinai (Yearbook of the Hokhmat Israel Society in Rumania 1933 ) pág. 10; Sefer ha-Še elot (primera versión), Paris, Bibliothèque Nationale de France, MS Héb. 1056, fol. 62b; Rešit Hojmah, en R. LEVY y F. CANTERA (eds.), The Beginning of Wisdom. An Astrological Treatise by Abraham Ibn Ezra (Baltimore - London 1939) pág. LVII. Véanse también los siguientes pasajes en la obra exegética de Ibn Ezra: primer comentario a Gen 2,3; 4,14; 8,21; 31,19; segundo comentario a Gen 2,3; 4,1; 4,14; comentario largo a Ex 3,15; 6,3; 7,3; 20,23; 23,$25 ; 26,1 ; 33,21$; comentario corto a Ex 3,$13 ; 32,1$; comentario a Lev 19,4 ; a Num 21,8;22,28; a Deut 8,$3 ; 31,16$; a Sal 16,9;24,1; introducción al comentario a Eclesiastés y a Ecl 7,10.

${ }^{33}$ Comentario a la Torá, pág. 161.

${ }^{34}$ Para expresar el concepto de las siete esferas de los planetas, Ibn Ezra hizo uso de la expresión siv'a me 'onot, literalmente 'siete mansiones', que extrajo de Baraita de-Mazalot, una obra astrológica hebrea cuya exacta fecha de composición es imposible de precisar, pero que aparentemente fue escrita a comienzos de la Edad Media. Véase Baraita de-Mazalot en Ozar Midrašim, ed. J. D. EISENSTEIN (New York 1928) pág. 282.

${ }^{35}$ Vid. supra, nota 17. 
¿cómo podrían [las Escrituras] decir en el firmamento de los cielos (Gen 1,14) si no fuese mi interpretación correcta? Esta es la explicación de haya luminarias: que sean vistas en el firmamento, para diferenciar el día de la noche, porque cuando el sol se oculta, cuando su sombra desaparece de la faz de la tierra, cuando es vista la sombra de la luna y se pueden ver tres estrellas ${ }^{36}$, entonces será de noche.

Si buscamos paralelismos, este es el pasaje correspondiente a aquel en el cual Ibn Ezra se refería al «gran sabio sefardí» en su primer comentario a Gen 1,14 (vid. supra). Sin embargo, dos grandes diferencias los separan. En primer lugar, en este segundo comentario Ibn Ezra se empeña en demostrar que el cosmos está dividido en ocho esferas, que era precisamente uno de los argumentos fundamentales que sustentaba su rival en el primer comentario. Muy instructiva es la metodología utilizada por Ibn Ezra para corroborar su posición. En primer lugar, trae en su defensa a los geómetras, y a continuación demuestra con la ayuda de las ocultaciones o conjunciones de los planetas que el cosmos debe estar necesariamente estructurado en la forma de ocho esferas concéntricas. En otras palabras: si todas las estrellas residiesen en una sola esfera -aduce Ibn Ezra-, todos los planetas deberían moverse a la misma velocidad, y en ese caso sería imposible observar que en ciertas ocasiones entran en conjunción ocultándose mutuamente ${ }^{37}$. En

${ }^{36} \check{\text { Sabat }} 35 \mathrm{~b}$ et passim.

${ }^{37}$ Estas conjunciones de los planetas son un dato de fundamental importancia para Ibn Ezra. No es en vano que en este caso se esfuerce por expresarse con gran precisión, afirmando que éstas se producen «tanto en longitud como en latitud». En la parte final de su segundo comentario, se preocupará Ibn Ezra de enfatizar que las conjunciones de los siete planetas se pueden dar en nada menos que ciento veinte combinaciones diferentes (vid. infra). Tengamos también en cuenta que para un astrólogo medieval como Ibn Ezra, profundamente influido por la astrología árabe, las conjunciones periódicas de Saturno y Júpiter representan el instrumento más fidedigno para interpretar la historia colectiva humana y pronosticar el futuro de la humanidad a todos los niveles. Sobre estas conjunciones, véase especialmente $\mathrm{K}$.

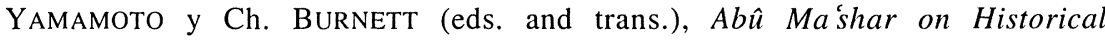
Astrology, The Book of Religions and Dynasties (On the Great Conjunctions) 
segundo lugar, si en el primer comentario atacaba al «gran sabio sefardí» por incluir dentro del firmamento a las ocho esferas, en el segundo Ibn Ezra se opone implícitamente a otro comentarista que pretendía situar los siete planetas en una sola esfera. Esta es la razón por la cual Ibn Ezra invertía tantas energías en demostrar lo absurdo de la idea de que todas las estrellas estén en una sola esfera. ¿Será que en el ínterin de esos diez años se han trastocado los papeles e Ibn Ezra ha cambiado totalmente su opinión sobre el significado de este versículo y, por ende, sobre el significado de la creación?

En realidad, desde un punto de vista exegético, no desde una perspectiva científica, la opinión del «gran sabio sefardí», que confundía el firmamento con las ocho esferas, y la opinión del contrincante anónimo de Ibn Ezra en su segundo comentario, que situaba el firmamento en una única esfera en la que estaban todas las estrellas, son muy similares. A fin de cuentas, los dos comentaristas confundían el firmamento con el cosmos en su totalidad y de esta manera sugerían que los cuerpos físicos de las estrellas fueron creados exnihilo. El hecho de que uno presentase un cosmos de ocho esferas y el otro un cosmos de una sola esfera es de gran interés histórico y científico, pero de menor importancia exegética -más tarde nos referiremos a esta importante diferencia entre los dos-. En última instancia, sin embargo, aunque ambos tenían una visión científica del mundo muy diferente, compartían una perspectiva similar de la creación del mundo. Demuestra ampliamente este último punto el hecho de que en los dos casos Ibn Ezra haya presentado contra ellos un argumento exegético idéntico -el texto de Gen 1,14, en el que se utiliza la expresión «el firmamento de los cielos» ${ }^{38}$ - y haya llegado

(Leiden 2000). Acerca de la postura de Ibn Ezra con respecto a estas conjunciones, véase S. SELA, Astrology and Biblical Exegesis, págs. 85-122.

${ }^{38}$ Pero, mientras que en el primer comentario Ibn Ezra, interesado en desbaratar el argumento del «gran sabio sefardí», afirmaba que «las Escrituras dicen 'en el firmamento de los cielos' (bi-reqi a ha-šamayim), para indicar que hay cielos que están sobre él [es decir, sobre el firmamento]», en el segundo y con una exagerada 
a una misma conclusión: que las luminarias y todas las estrellas fueron creadas en el firmamento para que allí pudieran ser vistas. Es también muy indicativo el hecho de que en los dos comentarios guardó Ibn Ezra completo silencio acerca de la formación física de las luminarias y de las estrellas. En otras palabras, el acto creador del cuarto día no se desarrolló en el mundo supralunar ni implicó la formación física de los cuerpos celestes. A continuación Ibn Ezra cambia el tema de su discurso y pasa a presentar las opiniones de otros comentaristas:

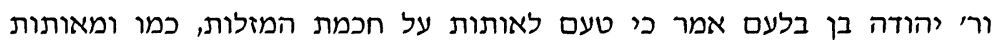

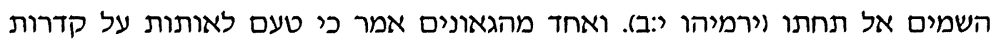

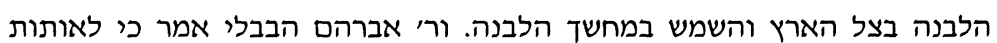

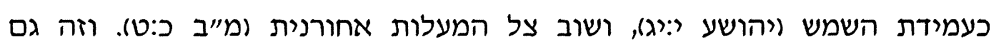

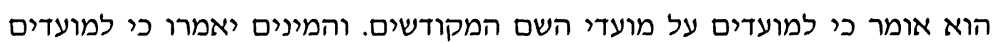

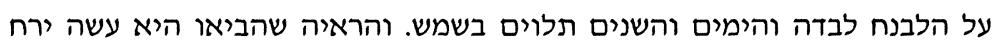

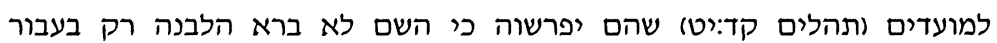

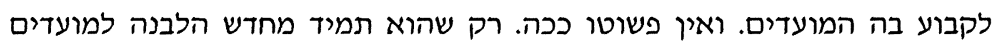

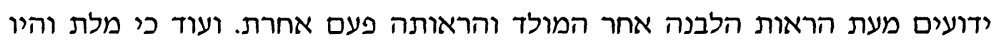

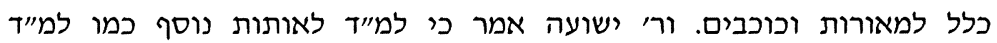

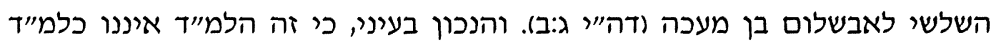

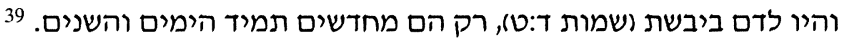

Y R. Yehudá Ibn Balaam afirmó que el sentido de le- otot está basado en la astrología ${ }^{40}$, según [el significado de] ni os aterréis por los signos celestes (Jer 10,2). Y uno de los geonim afirmó que el sentido de le- otot está relacionado con el eclipse de luna, [cuando entra] dentro de

confianza en su propia razón, aseveraba: «entonces, ¿cómo podrían [las Escrituras] decir 'en el firmamento de los cielos' si no fuese mi interpretación correcta?».

${ }^{39}$ Comentario a la Torá, págs. 161-162.

${ }^{40}$ En hebreo hojmat ha-mazalot, literalmente 'la ciencia de las constelaciones zodiacales'. Esta es una expresión sui generis acuñada por Ibn Ezra para denominar de forma colectiva a la astrología, astronomía, matemática, geometría y los cálculos relacionados con el cómputo del calendario. Para un estudio de esta expresión y sus diferentes usos en la obra de Ibn Ezra, véase S. SELA, «The Fuzzy Borders between Astronomy and Astrology as Reflected in the Thought and Work of Three Twelfth-Century Jewish Intellectuals», Aleph 1 (2001) págs. 84-86. 
la sombra de la tierra, y con el eclipse de sol, [cuando entra] dentro de la oscuridad de la luna. Y R. Abraham ha-Bablí afirmó que [el sentido de] le-'otot es como [el sentido de] se paró el sol [en medio del cielo] (Jos 10,13), y la sombra retroceda [diez grados] (2 Re 20,9). Y este ${ }^{41}$ también afirma que le-móadim se refiere a las festividades santas del Señor. Y los herejes ${ }^{42}$ dicen que le-móadim se refiere exclusivamente a la luna, y que los días y los años dependen del sol. La prueba que presentaron es hizo la luna le-moádim (Sal 104,19) que según ellos significa que el Señor no creó la luna sino para determinar las festividades (móadim). Pero esta no es la interpretación literal [del versículo]. En verdad [su significado] es que [el Señor] renueva la luna en unos tiempos (móadim) fijos, [que abarcan] desde que es visible la luna después del novilunio hasta su próxima visibilidad. Además, la palabra ve-hayu ${ }^{43}$ se refiere de forma general tanto a las luminarias como a las estrellas. Y R. Yešua afirmó que la lamed de le-'otot es redundante, como la lamed de el tercero Abšalom ${ }^{44}$ Ben Máakah $(1 \mathrm{Cr}$ $3,2)$. Y en mi opinión lo cierto es que esa lamed no es como la lamed de se convertirá en sangre ${ }^{45}$ sobre el suelo seco, sino que ellas ${ }^{46}$ renuevan siempre los días y los años.

Se observa claramente en este pasaje relativamente largo una característica fundamental del modus operandi de Ibn Ezra: el estudio de cualquier tema, tanto exegético como científico, debe ser presentado como una arena donde sabios de diferentes épocas, y aun de diferentes naciones y credos religiosos, lidian en un cuasi-académico intercambio de ideas ${ }^{47}$. Luciendo su habitual tono ecléctico, Ibn Ezra dedica entonces esta parte de su comentario a presentar la opinión de algunos de sus precursores en la exégesis bíblica judía acerca del significado de los términos claves le- otot y le-móadim.

\footnotetext{
${ }^{41}$ Es decir, Abraham ha-Bablí.

${ }^{42}$ En hebreo, minim.

${ }^{43}$ Es decir, 'servirán de'.

${ }^{44}$ En hebreo, le-Abšalom, y aquí está la lamed señalada por R. Yešua.

${ }^{45}$ En hebreo, le-dam, y aquí está la lamed señalada por Ibn Ezra.

${ }^{46}$ Es decir, las luminarias y las estrellas.

${ }^{47}$ Acerca de esta característica en la obra científica de Ibn Ezra, véase S. SElA, «Abraham Ibn Ezra's Scientific Corpus», págs. 145-147.
} 
Nos revela, en primer lugar, la opinión de Yehudá ibn Balaam, uno de sus antecesores en la España musulmana, que otorgaba un significado astrológico al término le $^{\text {- }}$ 'tot $^{48}$. A pesar de la extrema brevedad de esta referencia, la mención de Jer 10,2 como punto de apoyo nos da la pauta de que la interpretación de Yehudá ibn Balaam no era meramente astrológica, sino una alusión al estatus astrológico privilegiado de Israel con respecto a las demás naciones ${ }^{49}$. Luego Ibn Ezra pasa a presentar la opinión anónima de uno de los geonim, que entendió este termino como una alusión al eclipse de luna. Dignas de atención son la concisión, pero también la exactitud astronómica con la cual fueron descritos los eclipses de sol y luna ${ }^{50}$. Estas dos opiniones, que habían aparecido anónimamente en su primer comentario, son presentadas por Ibn Ezra con completa neutralidad ${ }^{51}$.

En lo que resta del pasaje, que ocupa su mayor parte, Ibn Ezra no se contenta ya con presentar otras interpretaciones, sino que pasa a atacar. Exhibe allí las opiniones de los caraítas, sus acérrimos y

\footnotetext{
${ }^{48}$ Acerca de Yehudá ibn Balaam, véase U. SIMON, «La escuela hispanojudía de exégesis bíblica», en Morešet Sefarad: El legado de Sefarad, ed. H. BEINART (Jerusalem 1992) págs. 126-128.

${ }^{49}$ El uso asociado de Jer 10,2 con un significado macro-astrológico se remonta al Talmud babilónico, Šabat 156b, donde este versículo bíblico es citado para demostrar que el pueblo de Israel está protegido de la influencia de las estrellas ('ein mazal le-Israel). Notamos a continuación un uso similar en Los capítulos de $R$. Eli ezer, parte VII. Un documento con contenido astrológico de la Geniza de El Cairo descubierto por S. D. Goitein revela un uso similar de este versículo. Véase S. D. GolTeIn, A Mediterranean Society, V (Berkeley 1967) págs. 329, 421. Para un uso similar en un entorno cronológico cercano a Ibn Ezra, véase la epístola de Abraham Bar Hiyya a Rabbi Judá Barzilai de Barcelona, publicada por Z. SCHWARZ, en Festschrift Adolf Schwarz, ed. S. KrauS (Berlin - Wien 1917) pág. 27.

${ }^{50}$ Esta descripción se encuadra dentro del marco de la crítica general que hace Ibn Ezra contra la exégesis bíblica de los geonim, quienes, en su opinión, emplearon exageradamente y de forma irrelevante las «sabidurías externas», o sea, las ciencias, y especialmente la astronomía, en su exégesis bíblica. En este sentido, se pueden ver los dos prefacios que escribió Ibn Ezra a sus dos comentarios al Pentateuco en Comentario a la Torá, págs. 1-2, 138-139.

${ }^{51}$ Pero nótese que en su primer comentario, aun sin aceptarlas, Ibn Ezra otorga a estas dos opiniones un claro carácter de probabilidad.
} 
perennes enemigos en todo lo relacionado con el calendario hebreo, quienes aparecen representados en forma particular por Abraham ha-Bablí y R. Yešua ${ }^{52}$ y son denominados colectivamente con el temible término de minim, que hemos traducido como 'herejes' ${ }^{53}$. El movimiento caraíta floreció en el siglo X y se arraigó en las comunidades judías orientales, bien lejos del entorno cronológico y geográfico en el cual se movió Ibn Ezra. Sin embargo, una característica peculiar que atrae la atención de cualquier lector atento de las obras de Ibn Ezra es que habitualmente, cuando trataba algún tema relacionado con el calendario hebreo, no desperdiciaba la ocasión de atacar ferozmente a los caraítas en general, o a alguno en particular. ¿Por qué se encarnizó tanto Ibn Ezra con los lejanos caraítas? ¿Se enfrentaba a contrincantes de carne y hueso, o a molinos de viento?

Al igual que los caraítas, que recurrían exclusivamente al texto bíblico para interpretar y aplicar los mandamientos de la religión judía en general, y los relacionados con la determinación del calendario en particular, Ibn Ezra otorgaba gran importancia al texto bíblico y a su significado literal. Pero aunque era un insuperable experto en las menudencias del texto bíblico, Ibn Ezra nunca fue conocido como un experto conocedor del Talmud. Por esta razón, es probable que estos feroces ataques contra los caraítas le pudieran haber servido como eficaz instrumento para distanciarse prudentemente de ellos. Es necesario tener también en cuenta que nuevas

\footnotetext{
52 Véase Encyclopaedia Judaica (Jerusalem 1971) vol. II, col. 158 s.v. Abraham HaBavli; vol. X, cols. 3-4, s.v. Jeshua Ben Judah.

${ }^{53}$ Es este un término ya usado en el Talmud para motejar a aquellos que surgen dentro de la comunidad judía pero presentan ideas que amenazan su integridad ideológica. Acerca del uso de este término en un entorno talmúdico, véase M. ORFALI, Talmud y Cristianismo (Barcelona 1998) págs. 45-55. Ibn Ezra, por su parte, utiliza el término, tanto en plural como en singular, en varias partes de su obra para vituperar a los caraítas. En plural, es utilizado en su comentario largo a Ex 12,6 y en su monografía 'Igeret ha-Šabat (La epístola del sábado), en M. FRIEDLANDER (ed.), Transactions of the Jewish Historical Society of England 2 (1894/5) pág. 73. En singular, el término min es utilizado admirablemente en los dos prefacios que escribió a sus dos comentarios a la Torá, Comentario a la Torá, págs. 2 y 138; lo utiliza también en su comentario largo a Ex 20,23 para motejar al caraíta Ben Zutah.
} 
pruebas documentales demuestran que la amenaza del movimiento caraíta contra el campo rabínico era bien real en el entorno cronológico y geográfico cercano a Ibn Ezra ${ }^{54}$. La amenaza caraíta, y la poderosa atracción que su lema de «retorno a las fuentes del judaísmo» despertaba en el seno de las masas judías, fue posiblemente la causa profunda que engendró dentro del campo rabínico y a partir del siglo XII la necesidad de la creación de un nuevo y notable género literario, compuesto por tratados dedicados a explicar el calendario judío desde un enfoque rabínico y escritos exclusiva y deliberadamente en la lengua hebrea ${ }^{55}$.

El fragmento del segundo comentario de Ibn Ezra a Gen 1,14 arriba mencionado es un excelente ejemplo de esta controversia. Por un lado, según Ibn Ezra, los caraítas esgrimen la palabra mo ádim que aparece tanto en Gen 1,14 como en Sal 104,19 para sostener que «el Señor no creó la luna sino para determinar las festividades», o sea, para afirmar que la principal razón que se oculta detrás de la creación de las luminarias es la determinación del tiempo ritual. Por otra parte, Ibn Ezra establece que esta opinión es totalmente errónea, ya que contradice completamente el significado literal no sólo de la palabra móadim, sino también de otros términos claves que aparecen en el texto de Gen 1,14. La expresión verbal ve-hayu, que aparece en plural, demuestra según Ibn Ezra que le-mo ádim no se refiere exclusivamente a la luna, sino a todos los cuerpos celestes, y que la palabra le-mo ádim, cuando hace alusión a este planeta, no debe ser entendida como una referencia al tiempo ritual, sino a los ciclos astronómicos del mismo. De la siguiente manera termina Ibn Ezra su comentario, pasando de lo particular a lo general:

\footnotetext{
${ }^{54}$ Yehudá ha-Leví, íntimo amigo de Ibn Ezra, relata en una de sus epístolas halladas en la Geniza de El Cairo que fue inducido a escribir su gran clásico, el Cuzari, nada menos que a consecuencia de una serie de preguntas que le planteó un caraíta que habitaba en la parte de España gobernada por los cristianos: véase S. D. GoITEIN, A Mediterranean Society, vol. V, pág. 456.

${ }^{55}$ Para una ampliación de estas ideas véase, S. SELA, Abraham Ibn Ezra and the Rise, págs. 277-280.
} 
כי הרגעים והעתות והיום והשנה וזמן התחברות משרת עם משרת, כמו המשרתים העליונים שיש להם מאה ועשרים מחברות, הכל תלוי במאורות

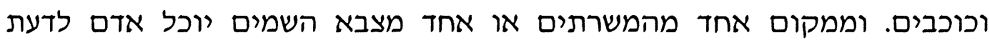

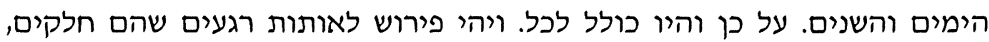

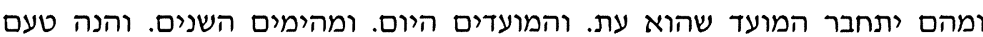

יהי מאורות: שיהיו נראים שיספר שתור אדם בהם.

Porque los momentos, los tiempos, el día, el año y el tiempo de la conjunción de un planeta con otro, como [en el caso de] los planetas superiores que se acoplan en ciento veinte conjunciones, todos ellos dependen de las luminarias y de las estrellas. Y desde la posición donde está ubicado alguno de los planetas o alguna [estrella] del ejército celeste, podrá el hombre conocer los días y los años. Por lo tanto ve-hayu ${ }^{57}$ incluye a todos. El significado de le-'otot, entonces, es 'momentos', que son partes, y ellos se sumarán para producir el mo éd, que es el tiempo. Y los mo ádim se acumularán para producir el día, y los días para producir los años. Y este es el significado de haya luminarias: que sean vistas para que el hombre pueda computarlas.

Hemos visto ya cómo en su primer comentario Ibn Ezra insinuaba lacónicamente que 'otot y mo ádim significan, respectivamente, 'minutos' y 'horas', es decir, dos períodos del tiempo cíclico (vid. supra). Ahora, apoyándose en su demoledor ataque contra los caraítas, pasa Ibn Ezra a sacar conclusiones generales. En su opinión, todos los enigmáticos términos que en este versículo aluden de una manera u otra al tiempo - otot, mo'adim, yamin, šanim- son unidades cronológicas interrelacionadas que hacen referencia a los diferentes períodos del tiempo cíclico. 'Otot, el primer elemento de la lista, no significa, como piensan los caraítas, 'señales' del tiempo ritual, sino 'momentos', que no son sino «partes», o sea, unidades básicas para la computación del tiempo cíclico. Todos los demás términos cronológicos que aparecen en este versículo son el resultado del cálculo

\footnotetext{
${ }^{56}$ Comentario a la Torá, págs. 161-162.

${ }^{57}$ Es decir, 'servirán de'.
} 
acumulativo de estas «partes» del tiempo ${ }^{58}$. Así, los mo ádim son el producto de la acumulación de los otot; los yamin, es decir, 'los días', son el producto del cálculo acumulado de mo ádim; y aquellos a su vez se suman para producir los šanim, o sea, 'los años'. Muy natural nos parece este singular enfoque del tiempo cíclico en el caso de Abraham Ibn Ezra. Además de escribir sobre astrología, astronomía y matemáticas, Ibn Ezra compuso cuatro manuales dedicados a la descripción y a la explicación de los usos del astrolabio ${ }^{59}$. Leyendo estos tratados uno se entera no sólo de que algunos de los componentes físicos del astrolabio estaban específicamente dedicados a marcar el tiempo ${ }^{60}$, sino también de que este instrumento podía, mediante la observación del sol y de las estrellas, funcionar como un reloj, tanto de día como de noche ${ }^{61}$. Por lo

\footnotetext{
${ }^{58}$ Posiblemente lo que Ibn Ezra tenía presente cuando usaba el término 'partes' (halaqim) son las llamadas 'partes de Israel' (helqei Israel), que representan la división de la hora en 1080 partes y que, según la evidencia de pensadores hispanojudíos como Abraham Bar Hiyya, Maimónides, Yehudá ha-Leví y Abraham Ibn Ezra, era utilizada por los antiguos sabios de Israel para cálculos relacionados con el calendario. Ibn Ezra utiliza este término en su comentario largo a Ex 12,2.

${ }^{59}$ Tres de los manuales fueron escritos en hebreo y fueron titulados Keli haNehošet. El cuarto fue dictado por Ibn Ezra a un alumno. Para estos cuatro manuales, véase S. SELA, «Abraham Ibn Ezra's Scientific Corpus», págs. 104-114.

${ }^{60}$ En la parte delantera del astrolabio estaban grabadas once líneas destinadas a medir las doce horas torcidas de la noche y del día, que eran el resultado de dividir cada día y cada noche del año en doce partes iguales. Además, en el borde de la parte trasera del astrolabio había varios aros concéntricos, dos de ellos divididos en 365 y 12 partes, con los cuales era posible calcular los días y los meses del año. Véase, por ejemplo, Keli ha-Nehošet, primera versión, ed. H. EDELMAN (Koenisberg 1845) págs. 9 y 11. Véase también la versión latina en J. M. MiLlás VALLICROSA, «Un nuevo tratado de astrolabio de R. Abraham ibn Ezra», Al-Andalus 5 (1940) pág. 11.

${ }^{61}$ Una parte considerable de los procedimientos explicados por Ibn Ezra en sus manuales estaba dedicada al cómputo del tiempo, el cual se realizaba por medio de la observación de los movimientos del sol durante el día, y de las estrellas fijas de la octava esfera durante la noche. Con respecto a este cómputo durante el día puede consultarse la segunda version de Keli ha-Nehošet, Mantova, Biblioteca di Mantova, Fondo Ebraico Mantovano, MS Ebr. 10, fols. 40b-41a, y, en la version latina, «Un nuevo tratado», pág. 13. Con respecto al cálculo del comienzo del año tropical, véase la segunda versión, fol. 46b. Con respecto al cálculo del tiempo
} 
tanto, en el caso de un experto astrolabista como Ibn Ezra, no nos deberían asombrar sus afirmaciones de que «los momentos, los tiempos, el día, el año ... todos ellos dependen de las luminarias y de las estrellas», y de que «desde la posición donde está ubicado alguno de los planetas o alguna [estrella] del ejército celeste, podrá el hombre conocer los días y los años».

Un examen a fondo nos permite observar que Ibn Ezra también lucía en la parte final de su comentario su calidad de cosmólogo, e incluso de teólogo. Leemos allí que «el tiempo de la conjunción de un planeta con otro, como en el caso de los planetas superiores, que se acoplan en ciento veinte conjunciones, todos ellos dependen de las luminarias y de las estrellas». Ibn Ezra extrajo la idea de las ciento veinte conjunciones del Centiloquium, un popular y famoso tratado astrológico apócrifamente atribuido en la Edad Media a Claudio Tolomeo ${ }^{62}$. Abraham Ibn Ezra, adicto a los cálculos de

\footnotetext{
durante la noche observando la posición de alguna de las estrellas fijas gravadas en el rete del astrolabio, véase la segunda versión, fol. 43a y, en la versión latina, pág. 20.

${ }^{62}$ Este tratado tuvo amplia circulación en el seno de la civilización árabe, en la cual fue titulado Kitab al-Tamara, y en la civilización latina, donde fue conocido con los nombres de Centiloquium o Liber Fructus. Fue traducido al hebreo en el siglo XIII por Kalonimus ben Kalonimus con el nombre Sefer ha-Peri, ha-niqrah Meah Diburim (Paris, Bibliothèque Nationale de France, MS Héb. 1055, fols. 52 $2^{\text {- }}$ $72^{a}$ ). El mismo tratado era conocido por Ibn Ezra con el nombre de Sefer ha'llan (Libro del árbol) o Sefer ha-Peri (Libro del fruto). Véase Sefer ha-Moladot, Paris, Bibliothèque Nationale de France, MS Héb. 1056, fol. 49a; Rešit Hojmah, en R. LeVy y F. CANTERA (eds.), The Beginning, pág. LXXVI. Sólo últimamente se ha establecido que la atribución del Centiloquium a Claudio Tolomeo no es sino una falsificación realizada por el distinguido matemático egipcio Ahmad b. Yusuf alMisri (835-912). Para esta opinión, véanse las siguientes obras: M. PLESSNER, «Batlmiyûs», Encyclopedia of Islam (Leiden 1960) I, págs. 1100-1102; D. SCHRADER, «Ahmad b. Yusuf», Dictionary of Scientific Biography (New York 1970) I, págs. 82-83; R. LEMAY, «The True Place of Astrology in Medieval Science and Philosophy», en Astrology, Science and Society, ed. P. CURRY (Suffolk 1987) págs. 58-59, nota 1, 70-71; Abû Ma shar al-Balhi (Albumasar), Kitâb al-madhal al-kabîr ila sinâ 'at ahkâm al-nujûm, Liber introductorii maioris as scientiam judiciorum astrorum, Edition critique par R. LEMAY (Napoli 1996) I, págs. 263, 269.
} 
combinaciones y creyente de que los secretos de la divinidad pueden ser revelados por medio de un análisis combinatorio de los valores de las letras del Tetragrammaton, se quedó fascinado por el significado cosmológico de la proposición quincuagésima del Centiloquium ${ }^{63}$. En su comentario largo a Ex 33:21 y en la introducción a la primera versión de su Sefer ha- 'Olam (Libro del mundo), exponía magistralmente y en forma paralela los procedimientos combinatorios de los cuales resultaba que «ciento veinte» es precisamente el número de todas las posibles combinaciones en las que pueden entrar en conjunción (es decir, combinarse) los siete planetas ${ }^{64}$. Introdujo la misma idea en sus monografías teológicas, donde el número «ciento veinte» representaba las posibles combinaciones de las dos primeras letras del Tetragrammaton ${ }^{65}$, y también en varios comentarios bíblicos de estratégica importancia, donde las ciento veinte conjunciones cumplían la función de una constante cosmológica con la capacidad de explicar los múltiples y complejos movimientos de los cuerpos celestes y los principios del tiempo cíclico ${ }^{66}$. Su segundo comentario a Gen 1,14 es un ejemplo más de este tipo.

\footnotetext{
${ }^{63}$ Esta proposición era citada en Barcelona en la segunda mitad del siglo XIV por el astrónomo Dalmau Ses Planes, en el prefacio que compuso a las tablas astronómicas del Rey Don Pedro el Ceremonioso: «Ptolomeus vir in scientia stellarum peritissimus, exorator Centilogii sui propositione quinquagesima, sic ayt: "Non obliscaris causam 120 coniunctorum que sun in stellis erraticis. In illis enim est maior scientia eorum que fiunt in hoc mundo'». Véase este pasaje en Las Tablas Astronómicas del Rey Don Pedro el Ceremonioso, edición crítica de los textos hebraico, catalán y latino, con estudio y notas por J. M. Millás VAllicrosA (Madrid - Barcelona 1962) pág. 87.

${ }^{64}$ Véase comentario largo a Ex 33,21 en Comentario a la Torá, vol. II, pág. 217; Sefer ha- Olam (primera versión), Paris, Bibliothèque Nationale de France, MS Héb. 1056, fol. 80b. Para un análisis comparativo de estos dos pasajes, véase $S$. SELA, Astrology and Biblical Exegesis, págs. 72-84.

${ }^{65}$ Para demostrarlo, utilizaba Ibn Ezra con respecto a los valores de las letras del Tetragrammaton la misma fórmula combinatoria que había utilizado con respecto a las combinaciones de los siete planetas. Véase Abraham Ibn Ezra, Sefer Yesod Morah ve-Sod Torah, en Abraham Ibn Ezra: Reader, pág. 340.

${ }^{66}$ Ibn Ezra utilizó las ciento veinte conjunciones en su comentario largo a Ex 3,13 y 33,21 , en su comentario largo a Dan 10,21 y en su comentario a Ecl 1,3.
} 
Completa así Ibn Ezra su opinión sobre el cuarto día de la creación. El relato bíblico sobre este día no se refiere ni a la creación ex-nihilo del mundo supralunar, ni a la creación física de los cuerpos físicos de las luminarias y de las estrellas. En la frase final de su comentario, Ibn Ezra reiteraba su opinión de que la descripción bíblica de la creación del cuarto día representa un fenómeno eminentemente visual, en cuyo marco las estrellas pudieron ser vistas por primera vez, pero agregaba un detalle importante: «este es el significado de haya luminarias: que sean vistas para que el hombre pueda computarlas». En otras palabras: la descripción bíblica del cuarto día no relata la creación del tiempo ritual, sino la génesis del tiempo cíclico, que para un científico medieval no significa otra cosa que la computación del movimiento cíclico de los cuerpos celestes. Todo esto fue posible a partir del cuarto día, ya que sólo después de que las estrellas pudieron ser vistas fue posible computar su movimiento cíclico.

\section{CONCLUSIÓN}

Algunas declaraciones de Ibn Ezra, influido como otros intelectuales hispanojudíos contemporáneos por teorías en boga de origen indio, nos permiten conjeturar que apoyaba la teoría de ciclos cósmicos de creación y destrucción ${ }^{67}$. En su Liber de rationibus tabularum, después de haber descrito estos ciclos según el sistema de Sind Hind, Ibn Ezra afirmaba que «ista res cognosci non potuit nisi per prophetam» ${ }^{68}$. Si se tiene en cuenta que el autor de este

\footnotetext{
${ }^{67}$ Vid. supra la afirmación de Yehudá ha-Leví en su Cuzarí «de que el presente mundo fue precedido por innumerables mundos anteriores». Véanse también afirmaciones similares de Abraham Bar Hiyya en Sefer Megilat ha-Megale, págs. $10-11$.

${ }^{68}$ «Iam dixi quod ... medius cursus omnium planetarum secundum indos sumptus est a diebus Acintdeindi, qui dixerunt Dominum omnes planetas in capite Arietis creasse et dies mundi dixerunt esse 1000000000000 et adhuc 77000000000 et adhuc 215000000 et adhuc 450000 , et secundum eos omnis planeta revertitur ad
} 
tratado astronómico latino no ocultaba su identidad judía, se debe entender que esta referencia estaba apuntando a uno de los profetas bíblicos. Efectivamente, en tres comentarios bíblicos por lo menos tiende Ibn Ezra a apoyar la interpretación talmúdica que se hizo a Ez 48,35, según la cual el número 18.000 de este versículo debería ser entendido como una referencia al hecho de que el mundo fue creado y destruido 18.000 veces ${ }^{69}$. Sea como sea, a pesar de que diez años separan los dos comentarios estudiados en este artículo, es notable que casi todos los elementos discernibles en el segundo están ya implícita o explícitamente presentes en el primero. Este es un claro signo de la unidad y la coherencia en el pensamiento de Abraham Ibn Ezra.

Sin embargo, si uno se abstrae de los componentes ideológicos, estos dos comentarios aparecen ante el lector como bien diferentes el uno del otro. Si el primer comentario al Pentateuco fue denominado «el corto», lo fue por la simple razón de que cuando es comparado con el segundo, compuesto diez años más tarde en Francia, es sumamente conciso y lacónico. En cambio, si el segundo comentario fue denominado «el largo», lo fue porque en él Ibn Ezra estuvo dispuesto a ampliar y a explicar con más detalle sus argumentos y opiniones. Un excelente ejemplo particular que demuestra la idoneidad de estos apelativos son los dos comentarios a Gen 1,14: mientras que el segundo se extiende a lo largo de 350 palabras, el

punctum sui loci sine fraccionis superadictione ... Ego autem dico quod sensus humanus non capit aliquem in falibili arte adeo peritum posse esse ... dicimus ergo quod ista res cognosci non potuit nisi per prophetam»: J. M. Millás Vallicrosa (ed.), El Libro de los Fundamentos de las Tablas Astronómicas de R. Abraham Ibn Ezra (Madrid - Barcelona 1947) pág. 89.

${ }^{69}$ Véase especialmente el segundo comentario a Gen 1,1 (Comentario a la Torá, pág. 157) donde Ibn Ezra escribe: «y encontramos en las declaraciones de nuestros sabios que Dios creó 18.000 mundos. Esto es cierto, pero no hay que entenderlo literalmente. Y el entendido entenderá». Véanse también los dos comentarios a Gen 8,22 (Comentario a la Torá, págs. 43 y 183), donde hace aproximadamente las mismas declaraciones. 
primero ocupa sólo 114. Pero sería un error ver en este detalle un mero dato estadístico. El hecho de que Ibn Ezra haya tenido que escribir un segundo comentario al Pentateuco demuestra que, a pesar de pasar los años y de cambiar su entorno geográfico, la atracción que despertaba su obra exegética seguía siendo la misma. Pero, si después de haber escrito un comentario corto pasó a escribir otro largo, esto no sólo demuestra que Ibn Ezra pensó que sería conveniente adoptar un estilo algo más locuaz, sino que también sugiere que este cambio en su estrategia explicativa fue exigido por un nuevo público de lectores. En otras palabras: después de diez años de vagabundear por Italia y Francia, Ibn Ezra se estaba adaptando a su nuevo ambiente cultural.

Las diferencias entre los dos contrincantes con los cuales discute en sus dos comentarios a Gen 1,14 reflejan fielmente la diferencia entre los dos públicos de lectores a los cuales Ibn Ezra pensaba dedicar ambas obras. A pesar de que, como ya hemos observado, al apodar a Mar Hasán «gran sabio sefardí», la intención de Ibn Ezra no era tanto elogiarlo como denigrarlo, debemos también conceder que el «gran sabio sefardí» era presentado por Ibn Ezra como un instruido intelectual, versado en las ciencias y conocedor de la concepción científica del mundo en su tiempo, concepción que compartía con Ibn Ezra. Debemos también poner atención en el apodo de «sefardí», el cual nos deja intuir que Ibn Ezra estaba en realidad dedicando su obra a una audiencia hispanojudía, y que quizá todavía soñaba con retornar a su patria ${ }^{70}$. La extrema brevedad y concisión de su primer comentario nos da también la impresión de que estaba

\footnotetext{
${ }^{70}$ En el prefacio al primer comentario al Pentateuco, en el marco de una crítica a la exégesis bíblica de los geonim, invita Ibn Ezra a sus lectores a aprender las «sabidurías externas» -o sea, las ciencias- de los libros de los expertos [en esas ciencias] (véase Comentario a la Torá, pág. 2). Está totalmente claro que sus alumnos y lectores en Luca a mediados del siglo XII no tenían a su disposición ninguna biblioteca donde poder leer esa clase de libros. Por lo tanto, es razonable pensar que Ibn Ezra estaba dedicando este comentario a un público hispanojudío que, tal como él lo conoció antes de emigrar a Italia, residía en una de las zonas más avanzadas culturalmente de la Europa occidental.
} 
dedicado a un público muy culto, al cual era posible hablar sin ambages y sin necesidad de explicaciones preparatorias.

En contraste con su primer comentario, Ibn Ezra se presenta a sí mismo en el segundo discutiendo con otro comentarista que presenta en su favor datos astronómicos desprovistos de toda sofisticación teórica y que ignora totalmente la imagen científica del mundo vigente en su tiempo. Es notable también que Ibn Ezra, para convencer en un entorno exegético a su científicamente tosco rival, no sólo pusiese desmedida atención en algunos detalles técnicos referentes a las conjunciones entre los planetas, sino que también haya recurrido al apoyo de los geómetras, científicos que, de acuerdo con la mentalidad medieval, eran los más aptos para otorgar veracidad y fiabilidad a las observaciones empíricas de los astrónomos. Esto apunta, muy posiblemente, a la calidad del público al cual pensaba Ibn Ezra dedicar su segundo comentario. Se trataba, en primer lugar, de lectores desconocedores de los últimos adelantos de la ciencia, pero se trataba también de un público ávido por compenetrarse con la nueva ciencia greco-árabe, que justamente a mitad del siglo XII estaba siendo aceleradamente absorbida por las capas cultas de la Europa occidental. Ibn Ezra fue el principal transmisor de esta ciencia a las comunidades judías de Italia, Francia e Inglaterra, y en este sentido es importante señalar que los argumentos que empleaba para convencer a su tosco contrincante en el segundo comentario a Gen 1,14 (vid. supra) eran básicamente los mismos que utilizaba en la introducción a la segunda versión del Sefer ha-Te amim ${ }^{71}$ para demostrar que el cosmos está estructurado en la forma de ocho esferas concéntricas:

והנה ראינו, כי הגלגלים הם שבעה, בעבור שבעה משרתים, כל אחד בגלגלו, והמשלים תנועתו בימים מעטים הוא למטה מהמשלים תנועתו בימים רבים ממנו:

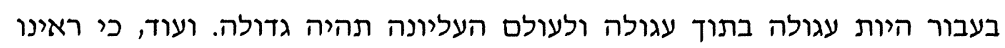

\footnotetext{
${ }^{71}$ Sobre este tratado astrológico, véase S. SELA, «Abraham Ibn Ezra's Scientific Corpus», págs. 121-126.
} 
כאשר יתחבר אחד מהמשרתים עם חברו יסתיר השפל את העליון והמשרתים

Y hemos observado que siete son las esferas, cada una de ellas [destinada] a cada uno de los siete planetas. Y la esfera de aquel planeta que describe su órbita en menos días está por debajo de la esfera del que describe una órbita en un mayor numero de días. Esto queda comprobado por el hecho de que, si describimos una circunferencia dentro de otra, siempre la exterior es la mayor. Y además hemos observado que si un planeta está en conjunción con otro, esto ocurre porque el planeta más bajo oculta al más alto, y además los planetas ocultan a las estrellas [fijas] del zodíaco.

He traído a colación este pasaje no sólo para mostrar la gran afinidad que muchas veces existe entre los argumentos que utiliza Ibn Ezra tanto en su obra científica como exegética, sino también para destacar que la similitud entre estos dos fragmentos nos induce a pensar, en este caso, que tanto el segundo comentario a Gen 1,14 como la segunda versión del Sefer ha-Te amim fueron destinados a un mismo público, es decir, los alumnos y lectores de Ibn Ezra durante su estancia en Ruán ${ }^{73}$.

${ }^{72}$ Sefer ha-Téamim (segunda versión), ed. N. BEN MENACHEM (Jerusalem 1941) pág. 2.

${ }^{73}$ Con respecto a la estancia de Ibn Ezra en Normandía, véase N. GOLB, The Jews in Medieval Normandy, págs. 3-5 y 264-267. 


\section{RESUMEN}

El propósito de este artículo es averiguar la opinión de Abraham Ibn Ezra (ca. 1089 - ca. 1167) sobre lo relacionado con la creación del mundo supralunar. Una característica fundamental del modus operandi de Ibn Ezra es que, si buscamos información acerca de su opinión sobre la creación del mundo, tanto sublunar como supralunar, no la hallaremos en sus tratados científicos astronómicos o astrológicos, sino precisamente en sus comentarios bíblicos. Por lo tanto, la metodología más adecuada consistirá en concentrar nuestros esfuerzos en el estudio meticuloso de sus dos comentarios a Génesis 1,14. Dado que este verso bíblico tiene como objetivo principal el relato y la descripción de la creación de las luminarias, pensamos que en ambos comentarios Ibn Ezra no pudo haber eludido dar su verdadera opinión -o al menos dejar alguna pista significativa- sobre la creación del mundo supralunar.

PAlABRAS ClAVE: Abraham Ibn Ezra, Génesis, astronomía, estrellas, exégesis, exnihilo, supralunar.

\section{SUMMARY}

This article aims at elucidating Abraham Ibn Ezra's (ca. 1089 - ca. 1167) opinion about the creation of the supra-lunar world. A major and striking feature of Ibn Ezra's approach is that he did not find it convenient to address this issue, intimately related to the nature of the celestial bodies, in his astronomical or astrological treatises, but rather in his biblical commentaries. Therefore, we propose to concentrate our efforts on the meticulous study of the two commentaries which Ibn Ezra wrote on Genesis 1,14. As this verse focuses on the account of the creation of the heavenly bodies, we have assumed that the elusive Ibn Ezra could not have avoided revealing his view, or, at least, that we should have left some significant hints from which we may uncover his genuine opinion about the creation of the supra-lunar world.

KEYWORDS: Abraham Ibn Ezra, Genesis, astronomy, stars, exegesis, ex-nihilo, supra-lunar. 